\title{
Endothelium-dependent and endothelium- independent vasorelaxant effects of unripe Rubus coreanus Miq. and Dendropanax morbiferus H. Lév. extracts on rat aortic rings
}

Soyi Park, Ki Hoon Lee, Wan Seok Kang, Jin Seok Kim and Sunoh Kim (i)

\begin{abstract}
Background: Many clinical trials on antihypertensive drugs have confirmed the usefulness of these drugs in regulating blood pressure effectively. However, all the drugs usually require long-term use; thus, economic burdens as well as some adverse effects, including headache, diarrhea, skin rash, edema, fever, and liver and kidney dysfunction, accompany their use. Therefore, we attempted to identify natural medications for treating hypertension. We investigated the antihypertensive effects of Dendropanax morbiferus H. Lév. extract (DP), enzymatically hydrolyzed DP extract (Hy-DP) and 5\% unripe Rubus coreanus Miq. ethanol extract (5-uRCK).

Methods: Extracts of the unripe $R$. coreanus were made using 20 volumes of $5 \%$ ethanol at $100^{\circ} \mathrm{C}$ for $4 \mathrm{~h}$. The dried leaves of $D$. morbiferus were subjected to enzymatic hydrolysis by protease, trypsin, bromelain and papain to increase $\mathrm{L}^{-}$ arginine and GABA levels. Vasorelaxant effects of these extracts were evaluated on rat aorta precontracted with phenylephrine. In addition, hippocampal neurons, RAW 264.7 macrophages and human umbilical vein endothelial cells (HUVECS) were used to exam nitric oxide (NO) production and NO synthase (NOS) gene expression.

Results: $D P, H y-D P$ and 5-URCK dose-dependently relaxed isolated rat aortic rings contracted with phenylephrine; however, Hy-DP was more effective than DP. L-NAME and ODQ differentially inhibited Hy-DP- and 5-uRCK-induced relaxation; both L-NAME and ODQ completely blocked 5-URCK-mediated relaxation. Endothelium-denuded aortic ring relaxation was induced much less by $5-u R C K$ than by Hy-DP. Therefore, 5-uRCK and Hy-DP induced vascular relaxation by endothelium-dependent and partially endothelium-dependent mechanisms, respectively. Hy-DP and 5-uRCK induced eNOS gene expression and NO production in endothelial cells but did not change iNOS/nNOS expression or NO production in macrophages or neuronal cells. Both Hy-DP and 5-uRCK effectively induced vascular relaxation via similar but slightly different mechanisms. The best effective combination was investigated after mixing Hy-DP and 5uRCK at different ratios. The 2:1 Hy-DP:5-uRCK mixture inhibited ACE, CGMP- and CAMP-dependent phosphodiesterase activity and vascular relaxation better than the other mixtures.
\end{abstract}

(Continued on next page)

\footnotetext{
* Correspondence: sunoh@korea.ac.kr

Central R\&D Center, Bioresources and Technology (B\&Tech) Co., Ltd., 257,

Jebong-ro, Buk-gu, Gwangju 61239, South Korea
}

(c) The Author(s). 2020 Open Access This article is licensed under a Creative Commons Attribution 4.0 International License, which permits use, sharing, adaptation, distribution and reproduction in any medium or format, as long as you give appropriate credit to the original author(s) and the source, provide a link to the Creative Commons licence, and indicate if changes were made. The images or other third party material in this article are included in the article's Creative Commons licence, unless indicated otherwise in a credit line to the material. If material is not included in the article's Creative Commons licence and your intended use is not permitted by statutory regulation or exceeds the permitted use, you will need to obtain permission directly from the copyright holder. To view a copy of this licence, visit http://creativecommons.org/licenses/by/4.0/. The Creative Commons Public Domain Dedication waiver (http://creativecommons.org/publicdomain/zero/1.0/) applies to the data made available in this article, unless otherwise stated in a credit line to the data. 
(Continued from previous page)

Conclusion: In conclusion, Hy-DP and 5-uRCK exert antihypertensive effects through different endothelium-dependent or endothelium-independent mechanisms. These findings may greatly help elucidate the mechanisms of clinical efficacy of Hy-DP:5-uRCK mixtures used for blood pressure regulation.

Keywords: Unripe Rubus coreanus Miq., Dendropanax morbiferus H. Lév., Hypertension, L-arginine, GABA, Nitric oxide

\section{Background}

Studies on the prevention of hypertension have shown that nutritional intervention may reduce the necessary doses and adverse effects of drugs when used in combination with current pharmacologic treatments [1]. Therefore, nutritionbased approaches are recommended as first-line treatments for the prevention of hypertension in individuals with highnormal blood pressure and as add-on treatments to be used in combination with antihypertensive drugs in patients with hypertension at any stage [2].

Bokbunja refers to Korean black raspberry (Rubus coreanus Miq.) fruit and derived products, and is native to Korea, Japan, and China. Unripe $R$. coreanus is a functional food or nutraceutical supplement that is useful for the prevention of noncommunicable diseases, especially cardiovascular diseases (CVDs). We previously reported the effects of a $5 \%$ ethanol extract of unripe $R$. coreanus (5-uRCK) on CVD-related diseases such as hyperlipidemia and obesity [3-6]. The effects of this extract may reduce the risk for CVDs, including hypertension, atherosclerosis, stroke and myocardial infarction. One of the major active compounds in $R$. coreanus is ellagic acid, which has antiobesity and antioxidant properties $[7,8]$. The unripe fruits of $R$. coreanus are usually used as traditional medicine and might be more therapeutic than the ripe fruits. A recent report revealed that the unripe fruits of $R$. coreanus have a higher concentration of ellagic acid than the ripe fruits, which might be the reason why unripe fruits are traditionally used [9]. Furthermore, our previous study reported that ellagic acid is a major component of 5 - $u$ RCK $[4,6$, 10]. However, information about the antihypertensive effect of 5-uRCK is very limited.

Dendropanax morbiferus H. Lév., a subtropical tree called Hwangchil in Korea due to its golden color lacquer, belongs to the Araliaceae family. It is an endemic species in Korea and is found in the southwestern parts of the country and extracts from its roots and stems are traditionally used to treat migraine headaches, dysmenorrhea, and skin diseases [11]. Biologically active molecules in $D$. morbiferus leaf extract $(D P)$, including flavonoid and polyacetylene compounds, have antioxidant, anticancer, antidiabetic and antiatherogenic properties [12-14]. Recently, a report demonstrated that $D P$ contains phenolic compounds, including rutin, chlorogenic acid, $(+)$-catechin, ferulic acid, myricetin, quercetin, and resveratrol, that have anti-inflammatory effects [15]. In our previous study, we suggested quercetin as a marker compound of $D$. morbiferus after analyzing plant parts (fruits, sprouts, leaves, sprigs, and branches), harvest times, and extraction solvents for quality control [16]. In another study, we reported that ${ }_{L}$-arginine and $\gamma$-aminobutyric acid (GABA) levels in $D P$ were increased by enzymatic hydrolysis and

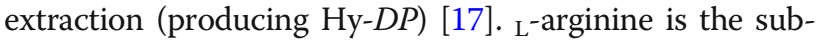
strate for nitric oxide (NO) synthesis, which is important for normal endothelial function [18]. GABA-rich products also significantly reduce blood pressure in mildly hypertensive patients [19]. It has been proposed that GABA, one of the depressive neurotransmitters in the central nervous system, plays an important physiological role in the regulation of cardiovascular function [20]. GABA is present in various kinds of common foods, including anaerobically treated tea [21] and fermented foods [22], and the antihypertensive activities of GABA [23] and GABAcontaining foods [24] have been reported.

Moreover, we recently reported an antiobesity effect of $D P$ [25]. However, information about the antihypertensive effect of $D P$ is very limited. Therefore, in this study, the antihypertensive effects of $D P$ and $\mathrm{Hy}-D P$ were investigated in an isolated rat aorta model, and the detailed mechanisms were explored. In addition, the Hy-DP/5-uRCK combination with the best antihypertensive effect was investigated.

\section{Methods \\ Reagents}

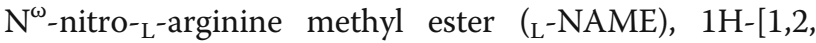
4] oxadiazolo[4,3-a]quinoxalin-1-one (ODQ), L-arginine, lipopolysaccharide (LPS; from Escherichia coli 0111:B4), phenylephrine hydrochloride (PHE) and angiotensinconverting enzyme (ACE) were purchased from SigmaAldrich (St. Louis, MO, USA). Acetylcholine chloride (ACh), glutamic acid and GABA were purchased from Tocris (Ellisville, MO, USA). Dulbecco's modified Eagle's medium (DMEM) and fetal bovine serum (FBS) were purchased from Invitrogen, Inc. (Grand Island, NY, USA). All other chemicals were of analytical grade.

\section{Animals}

Specific pathogen-free (SPF) grade healthy male Sprague-Dawley (SD) rats weighing 250 to $300 \mathrm{~g}$ each were purchased from Central Lab Animal, Inc. (Seoul, Republic of Korea). Animals were maintained at a constant room temperature of $22 \pm 2{ }^{\circ} \mathrm{C}$ with a humidity level of 
$50 \pm 5 \%$ and with free access to water and food under a 12:12 h light:dark cycle (lights on at 8:00 am). The animals were acclimatized for 4 days before the beginning of the experiments. All efforts were made to minimize animal suffering and to reduce the number of animals used. The experiment was conducted according to the international guidelines for the care and use of laboratory animals [26], and was approved by the institutional animal care and use committee (IACUC) of the Bioresources and Technology (B\&Tech) Co., Ltd., Republic of Korea (Approval number: BT-008-2017). When the experiment began, all rats were anesthetized with isoflurane and then sacrificed by cervical dislocation in accordance with the IACUC guidelines; the thoracic aorta of rats was carefully removed.

\section{Preparation of extracts}

The unripe $R$. coreanus fruits (specimen voucher number: BT-URCK001) used in this study were collected (May 2017) in Gochang County (Jeollabuk-do, Republic of Korea) and authenticated by Dr. Kim at B\&Tech, Gwangju, South Korea. Extracts of the unripe R. coreanus were made using 20 volumes of $5 \%$ ethanol at $100{ }^{\circ} \mathrm{C}$ for $4 \mathrm{~h}$ as described in our previous study [3-6]. The dried leaves of $D$. morbiferus (specimen voucher number: BT-DP001) used in this study were collected (December 2017) in Gangjin County (Jeollanam-do, Republic of Korea) and authenticated by Dr. Kim at B\&Tech. $D P$ and $H y-D P$ extraction was performed as described in our previous study [17]. Briefly, the dried leaves of $D$. morbiferus were subjected to enzymatic hydrolysis by protease, trypsin, bromelain and papain to increase ${ }_{L}$-arginine and GABA levels. After the leaves were hydrolyzed twice, extraction was performed with purified water at $100{ }^{\circ} \mathrm{C}$ for $4 \mathrm{~h}$, and the enzymes were inactivated. Normally, $20.4 \mathrm{~g}$ and $27.7 \mathrm{~g}$ of dried powder could be obtained from $100 \mathrm{~g}$ of unripe $R$. coreanus and $D$. morbiferus, respectively. The Hy-DP was then analyzed for the presence of $\mathrm{L}_{\mathrm{L}}$-arginine and GABA using the method described in our previous study [17].

\section{Ex vivo experiments for measurement of vascular responsiveness}

SD-rat thoracic aortas were resected and placed in fresh Krebs' buffer solution (in $\mathrm{mmol} / \mathrm{L} ; \mathrm{NaCl} 119, \mathrm{KCl} 4.7$, $\mathrm{CaCl}_{2} \cdot 2 \mathrm{H}_{2} \mathrm{O} 2.5, \mathrm{KH}_{2} \mathrm{PO}_{4} 1.2, \mathrm{MgSO}_{4} \cdot 7 \mathrm{H}_{2} \mathrm{O} 1.2, \mathrm{NaHCO}_{3}$ 25 and glucose 11 at $37{ }^{\circ} \mathrm{C}$ ) bubbled with $5 \% \mathrm{CO}_{2}$ and $95 \%$ $\mathrm{O}_{2}$. The adjacent connective tissues were carefully removed to avoid distention of the vessels and damage to the endothelium. As indicated, the endothelium was removed by rubbing the intimal surfaces of rings with a pair of forceps. The aortas were then cut into $2 \mathrm{~mm}$ long rings. In order to minimize the animals used, at least five rings were prepared per rat and the sample sizes usually were $10-25$ in our study. The smooth muscle tissue was stabilized in a chamber for $1 \mathrm{~h}$ with a resting tension of $2-3 \mathrm{~g}$ with saline changes every 20 min. Isometric contractions were recorded using a forcedisplacement transducer (AD Instruments, Castle Hill, NSW, Australia) under a resting tension of $1.5 \mathrm{~g}$. The rings were contracted again with $\mathrm{PHE}(10 \mu \mathrm{M})$ before construction of a concentration-relaxation curve upon treatment with either ACh or compounds. To determine the NO- or NOsensitive guanylate cyclase (GC)-mediated relaxation of compounds, the aortic rings were rinsed and exposed to $\mathrm{L}^{-}$ NAME $(10 \mu \mathrm{M})$, a NO synthase inhibitor; ODQ $(10 \mu \mathrm{M})$, a NO-sensitive GC inhibitor; or a mixture of ${ }_{\mathrm{L}}$-NAME and ODQ for $30 \mathrm{~min}$ before induction of steady contraction by PHE. The changes in vascular tension were recorded, and the vasodilation rate (\%) was calculated as:

\footnotetext{
Relaxation (\%)

$=($ maximal contraction by PHE

- tension at the corresponding time after incubation with tested compounds)

/ (maximal contraction by PHE - basal tension $) \times 100 \%$.
}

\section{Cell preparation}

Cultured hippocampal neurons were prepared using the method described in our previous study [27]. Briefly, the hippocampi were isolated from $16 \sim 18$-day-old fetal SD rats and incubated with $0.25 \%$ trypsin in Hanks's Balanced Salt Solution (HBSS) at $37^{\circ} \mathrm{C}$ for $20 \mathrm{~min}$. The cells were then mechanically dissociated with fire-polished Pasteur pipettes by trituration and plated at a density of $1 \times 10^{6} \mathrm{cells} / \mathrm{cm}^{2}$ on poly-${ }^{-}$-lysine-coated culture dish. The cells were maintained in Neurobasal/B27 medium containing $0.5 \mathrm{mM}_{\mathrm{L}}$-glutamine, $25 \mathrm{mM}$ glutamate, $25 \mathrm{mM}$ 2-mercaptoethanol, $100 \mathrm{U} / \mathrm{mL}$ penicillin and $100 \mu \mathrm{g} / \mathrm{mL}$ streptomycin under a humidified atmosphere of $95 \%$ air and $5 \% \mathrm{CO}_{2}$ at $37^{\circ} \mathrm{C}$. The cultures were fed twice a week with the same medium without glutamate. Experiments were carried out on neurons after 712 days in culture and after the neurons were incubated with $50 \mu \mathrm{M}_{\mathrm{L}}$-glutamate for $6 \mathrm{~h}$ as a positive control to induce nNOS.

Murine RAW 264.7 macrophages (40071) were obtained from the Korea Cell Line Bank (KCLB, Seoul, Korea) and cultured in DMEM. To induce an inflammatory state, the cells were grown until $70 \%$ confluence was reached and then incubated with $1 \mu \mathrm{g} / \mathrm{mL}$ LPS for 6 $\mathrm{h}$ as a positive control to induce iNOS.

HUVECs were obtained from the American Type Culture Collection (ATCC, Manassas, VA, USA). The cells were cultured in medium consisting of modified Kaigen's F-12 (ATCC) supplemented with 10\% FBS, $0.1 \mathrm{mg} / \mathrm{mL}$ heparin, and $0.03 \mathrm{mg} / \mathrm{mL}$ endothelial cell growth supplement (Upstate, Lake Placid, NY, USA). The cells were grown until $70 \%$ confluence was reached and then incubated with $10 \mu \mathrm{M}$ ACh for $6 \mathrm{~h}$ as a positive control to induce eNOS. 


\section{Gene expression analysis}

Gene expression in cultured cells was analyzed by RTPCR, as previously described [28]. Total RNA was extracted from the cultured cells using an easy-BLUE Total RNA Extraction Kit (iNtRON Biotechnology, Seongnam, Republic of Korea) according to the manufacturer's instructions. To synthesize cDNA, $1 \mu \mathrm{g}$ of total RNA was mixed with a premixture of oligo (dT) primers and incubated at $45^{\circ} \mathrm{C}$ for $60 \mathrm{~min}$. The specific primers that we used in this study were as follows: iNOS, $5^{\prime}$-CAGTTC TGCGCCTTTGCTCAT-3' (sense) and 5'-GGTGGT GCGGCTGGACTTT-3' (antisense); eNOS, 5'-GTGTTT GGCCGAGTCCTCACC-3' (sense) and 5'-CTCCTG CAAGGAAAAGCTCTG-3' (antisense); and nNOS, 5' CACATTTGCATGCATGGGCTCGA-3' (sense) and 5' CTCTGCAGCGGTATTCATTC-3' (antisense). Sense (5'-AGGCCGGTGCTGAGTATGTC-3') and antisense (5'-TGCCTGCTTCACCACCTTCT-3') primers for glyceraldehyde 3-phosphate dehydrogenase (GAPDH) were used as a control to measure the total RNA content of each sample. Linear amplification range for each gene was tested on the adjusted cDNA. The accumulation of gene transcript was determined by RT-PCR at the 27th cycle. Expression levels were quantified using a gel documentation and analysis system (ChemiDoc XRS+ System, BioRad, Sydney, Australia). A quantitative real-time RT-PCR technique was used to analyze the mRNA expression of eNOS. To normalize mRNA expression, the expression of the housekeeping gene GAPDH was used. The relative mRNA levels were quantified using the $\Delta \Delta \mathrm{Ct}$ method.

\section{NO production assay}

Various concentrations of 5- $u$ RCK and $\mathrm{Hy}-D P$ were prepared in phenol red-free medium to reduce assay interference by phenol red. Cell culture supernatants were collected after treatment with different compounds for $3 \mathrm{~h}$. NO production was detected spectrophotometrically via measurement of its final stable equimolar degradation products, nitrite $\left(\mathrm{NO}_{2}^{-}\right)$and nitrate $\left(\mathrm{NO}_{3}^{-}\right)$, by using nitrate reductase and via measurement of the acidcatalyzed diazotation reaction by using sulfanilamide and naphthyl ethylenediamine (Griess reaction). Total nitrite was quantified after the reduction of all nitrates with nitrate reductase. The nitrite levels in the culture supernatants were within the linear ranges of calibration curves that were generated from a solution of sodium nitrite. The total nitrite concentration was calculated from a standard curve constructed over the linear range of the assay and is expressed in $\mu \mathrm{g} / \mathrm{mL}$.

\section{Determination of ACE-inhibitory activity}

ACE-inhibitory activity was measured according to the method of Holmquist et al. [29] with some modifications. The total volume of $1.22 \mathrm{~mL}$ contained $20 \mu \mathrm{L}(20 \mathrm{mU})$ of commercial ACE $(1 \mathrm{U} / \mathrm{mL})$, a $200 \mu \mathrm{L}$ mixture of different amounts of compounds and $1 \mathrm{~mL}$ of $0.5 \mathrm{mM} \mathrm{N}$-(3-[2-fury1]acryloyl)-Phe-Gly-Gly). The decrease in absorbance reading at $345 \mathrm{~nm}\left(\Delta \mathrm{A}_{\text {inhibition }}\right)$ was recorded over $5 \mathrm{~min}$ at room temperature. Deionized water was used instead of sample solution to obtain a blank reading $\left(\Delta \mathrm{A}_{\text {blank }}\right)$. ACE activity is expressed as the ACE inhibition (\%) and was calculated as follows: $\left[1-\Delta \mathrm{A}_{\text {inhibition }} / \Delta \mathrm{A}_{\text {control }}\right] \times 100 \%$. The half-maximal inhibitory concentration $\left(\mathrm{IC}_{50}\right)$ was defined as the concentration of sample required to inhibit $50 \%$ of ACE activity under these conditions.

\section{CAMP or cGMP-dependent phosphodiesterase (PDE) activity inhibition assay}

The PDE activity inhibition of the compounds was examined using a PDE assay kit (Abcam, Cambridge, MA, USA). Briefly, $10 \mu \mathrm{L}$ of the compound in distilled water was mixed with $20 \mu \mathrm{L}$ of $0.5 \mathrm{mM} \mathrm{3} 3^{\prime} 5^{\prime}$-cGMP or $3^{\prime} 5^{\prime}$ cAMP substrate solution, $5 \mu \mathrm{L}$ of PDE assay buffer, $10 \mu \mathrm{L}$ of $5 \mathrm{kU} / \mu \mathrm{L} 5^{\prime}$-nucleotidase solution, and $5 \mu \mathrm{L}$ of $4 \mathrm{U} / \mathrm{mL}$ PDE solution in each well of 96-well microplates. The mixtures were incubated at $37^{\circ} \mathrm{C}$ for $60 \mathrm{~min}$. The absorbance of the mixtures was measured at 620 $\mathrm{nm}$ by a microplate reader (EPOCH 2, BioTek, Winooski, VT, USA). The inhibition of PDE activity was calculated by the following equation:

$$
\begin{aligned}
& \text { \%inhibition of PDE activity } \\
& \quad=\left[\mathrm{AR}_{\text {water }}-\left(\mathrm{AR}_{\text {sample }}-\mathrm{AC}_{\text {sample }}\right) / \mathrm{AR}_{\text {water }}\right] \times 100,
\end{aligned}
$$

where $\mathrm{AR}_{\text {water }}$ and $A R_{\text {sample }}$ are the absorbances of the mixtures obtained from the reaction of PDEs with distilled water and samples, respectively, and $\mathrm{AC}_{\text {sample }}$ is the absorbance of the control system (used to determine the phosphate content existing in the compounds).

\section{Statistical analysis}

Best-fit lines were computed for all concentration-response curves using the logistic equation:

$$
\mathrm{y} / \mathrm{y}_{\max }=1 /\left[1+\left(k_{1 / 2} /[\mathrm{A}]\right)^{\mathrm{nH}}\right],
$$

where $y_{\max }$ is the maximal response, $k_{1 / 2}$ is the concentration eliciting the half-maximal response $\left(\mathrm{EC}_{50}\right.$ or $\left.\mathrm{IC}_{50}\right),[\mathrm{A}]$ is the drug concentration, and $n_{\mathrm{H}}$ is the Hill coefficient.

The data are presented as the mean and standard error of the mean (SEM) from three independent experiments with replication. The data were statistically evaluated using Student's $t$-test or two-way analysis of variance (ANOVA) with GraphPad Prism 5 version 5.01 for Windows (GraphPad, Inc., San Diego, California, USA) software programs. Differences between groups were assessed using Duncan's multiple range tests. Statistical significance was indicated when $p<0.05$. 


\section{Results}

L-arginine and GABA contents of DP, Hy-DP and 5-uRCK As shown in Table 1, quantitative analysis by HPLC showed that the extracts $D P, \mathrm{Hy}-D P$ and 5- $u$ RCK contained $2.61 \pm 1.02 \mathrm{mg} / \mathrm{g}, \quad 17.77 \pm 1.36 \mathrm{mg} / \mathrm{g}$ and $1.63 \pm$ $0.25 \mathrm{mg} / \mathrm{g}$ L-arginine, respectively. GABA was also detected by a similar method.

\section{Effects of DP, Hy-DP and 5-uRCK on isolated rat aortic rings precontracted with $\mathrm{PHE}$}

As shown in Fig. 1, ACh concentration-dependently caused relaxation in PHE-precontracted $(10 \mu \mathrm{M})$ aortic rings with intact endothelia. Through preliminary screening of $u$ RCK extracts prepared by various extraction methods, we found that $5-u$ RCK had the highest vasorelaxant effect (data not shown). In addition, all our previous studies have indicated that $5-u$ RCK has the greatest antiobesity and antihypercholesterolemic effects of all tested $u$ RCK extracts [3-6]. As shown in Fig. 1b and g, 5-uRCK ( $\mathrm{EC}_{50}$ value: $\left.1.19 \pm 0.06 \mu \mathrm{g} / \mathrm{mL}\right)$ dosedependently relaxed endothelium-intact aortic rings precontracted with PHE. As shown in Fig. 1c and d, DP $\left(\mathrm{EC}_{50}\right.$ value: $\left.0.55 \pm 0.04 \mu \mathrm{g} / \mathrm{mL}\right)$ and $\mathrm{Hy}-\mathrm{DP}\left(\mathrm{EC}_{50}\right.$ value: $0.57 \pm 0.03 \mu \mathrm{g} / \mathrm{mL}$ ) also dose-dependently relaxed endothelium-intact aortic rings precontracted with PHE. The maximal relaxant effects of $D P$ and $5-u R C K$ on PHE-induced contraction were $78.01 \pm 2.86 \%$ and $93.84 \pm 2.50 \%$ at a concentration of $10 \mu \mathrm{g} / \mathrm{mL}$, respectively. Furthermore, the maximal relaxant effect of $\mathrm{Hy}$ $D P$ on PHE-induced contraction was $118.04 \pm 6.83 \%$ at a

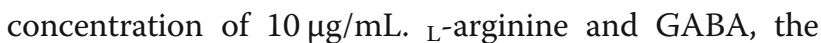
major components of $\mathrm{Hy}-D P$, also showed their own vasodilatory effects. Among them, $\mathrm{Hy}-D P$ exhibited the most potent vascular relaxant effect.

Effects of $\mathrm{L}-\mathrm{NAME}, \mathrm{ODQ}$ and endothelium denudation on DP-, Hy-DP- and 5-uRCK-induced relaxation in isolated rat aortic rings precontracted with $\mathrm{PHE}$

As shown in Fig. 2a and b, $D P$ - and $H y-D P$-induced relaxation was significantly inhibited by pretreatment with $\mathrm{L}^{-}$ NAME, ODQ or a mixture of ${ }_{\text {- }}$ NAME and ODQ in rat aortic rings with intact endothelia. Moreover, the use of the ${ }_{L}$-NAME and ODQ mixture almost completely inhibited 5- $u$ RCK-induced relaxation. Therefore, NO and GC

Table 1 L-Arginine and GABA contents in DP, Hy-DP and 5URCK. All results are expressed as the means \pm standard deviation of at least three separate experiments. ${ }^{* *} P<0.01$ and ${ }^{* * *} P<0.001$ vs DP

\begin{tabular}{lccll}
\hline $\begin{array}{l}\text { Amino } \\
\text { acid }\end{array}$ & MW & \multicolumn{3}{l}{$\begin{array}{l}\text { L-Arginine and GABA contents } \\
\text { (mg/g of extract) }\end{array}$} \\
\cline { 3 - 5 } & & $\mathbf{D P}$ & Hy-DP & 5-uRCK \\
\hline L-Arginine & 174.20 & $2.61 \pm 1.02$ & $17.77 \pm 1.36^{* * *}$ & $1.63 \pm 0.25$ \\
GABA & 103.12 & $15.53 \pm 3.10$ & $27.81 \pm 3.78^{* *}$ & $1.09 \pm 0.06$ \\
\hline
\end{tabular}

strongly affect the relaxant effect of $5-u R C K$ in an endothelium-dependent manner. Comparison between groups with intact $(+\mathrm{E})$ and denuded $(-\mathrm{E})$ epithelia revealed that the vasodilatory effect induced by $D P$ in rings with PHE precontraction was significantly impaired after physical removal of endothelial cells (Fig. 2c), which showed that vasodilation was partially endotheliumdependent. However, Hy-DP-induced relaxation in rat aortic preparations was more significantly inhibited $(36.69 \pm 4.82 \%)$ than $D P$-induced relaxation $(17.55 \pm$ $7.01 \%$ ) by denudation of the endothelial layer (Fig. 2d). The data indicate that $\mathrm{Hy}-D P$ might be responsible for partially endothelium-dependent vasorelaxation. 5-uRCK relaxed PHE-induced contractions in $+\mathrm{E}$ but not $-\mathrm{E}$ aortae $(85.06 \pm 2.82 \%$ inhibition), as shown in Fig. $2 \mathrm{c}$ and d. As shown in Fig. 2e, the 5- $u$ RCK-induced relaxation response occurred in a dose-dependent manner ( $E_{\max }$ value: $86.99 \pm 3.24)$, and this relaxation was inhibited by $\mathrm{L}^{-}$ NAME ( $E_{\max }$ value: $23.30 \pm 3.42$ ), ODQ ( $E_{\max }$ value: $29.02 \pm 2.72$ ) or aortic denudation ( $E_{\max }$ value: $24.99 \pm$ 2.19). The data indicate that $5-u \mathrm{RCK}$ might be responsible for endothelium-dependent vasorelaxation.

\section{A GABA receptor antagonist suppressed DP- and Hy-DP- induced vasorelaxation}

To examine endothelium-independent $D P$ - or Hy- $D P$ induced vasorelaxation in greater detail, whether the GABA receptor is involved in $D P$ - or $\mathrm{Hy}-D P$-induced vasorelaxation was further investigated. As shown in Fig. 3a, $100 \mu \mathrm{M}$ GABA typically relaxed PHE-induced vasocontraction in endothelial-intact aortae. Pretreatment with bicuculline (a GABA binding site antagonist) did not influence PHE-induced vasocontraction (data not shown), but it suppressed $D P$ - or $\mathrm{Hy}-D P$-induced vasorelaxation. Likewise, as shown in Fig. 3b and Fig. 3c, $D P$ - or $\mathrm{Hy}-D P$-induced vasorelaxation was suppressed by pretreatment with flumazenil (a benzodiazepinebinding site antagonist) and picrotoxin (a noncompetitive ionotropic GABA receptor antagonist).

\section{Effects of Hy-DP and 5-uRCK on NOS gene expression} NOS genes, such as iNOS, nNOS and eNOS, are differentially expressed in response to various stimuli, such as LPS, glutamate and ACh. RT-PCR analysis was performed to determine whether the effects of $D P, \mathrm{Hy}-D P$ and $5-u$ RCK on NO are related to modulation of the expression of NOSs. As shown in Fig. 4a, in LPSstimulated RAW 264.7 cells, iNOS was strongly expressed. However, iNOS expression was not increased by treatment with $D P, \mathrm{Hy}-D P$ or $5-u \mathrm{RCK}$. Likewise, as shown in Fig. 4b, nNOS expression was not increased by treatment with $D P, \mathrm{Hy}-D P$ or $5-u \mathrm{RCK}$ in cultured hippocampal neurons, but nNOS was strongly expressed in glutamate-stimulated cultured hippocampal neurons. 

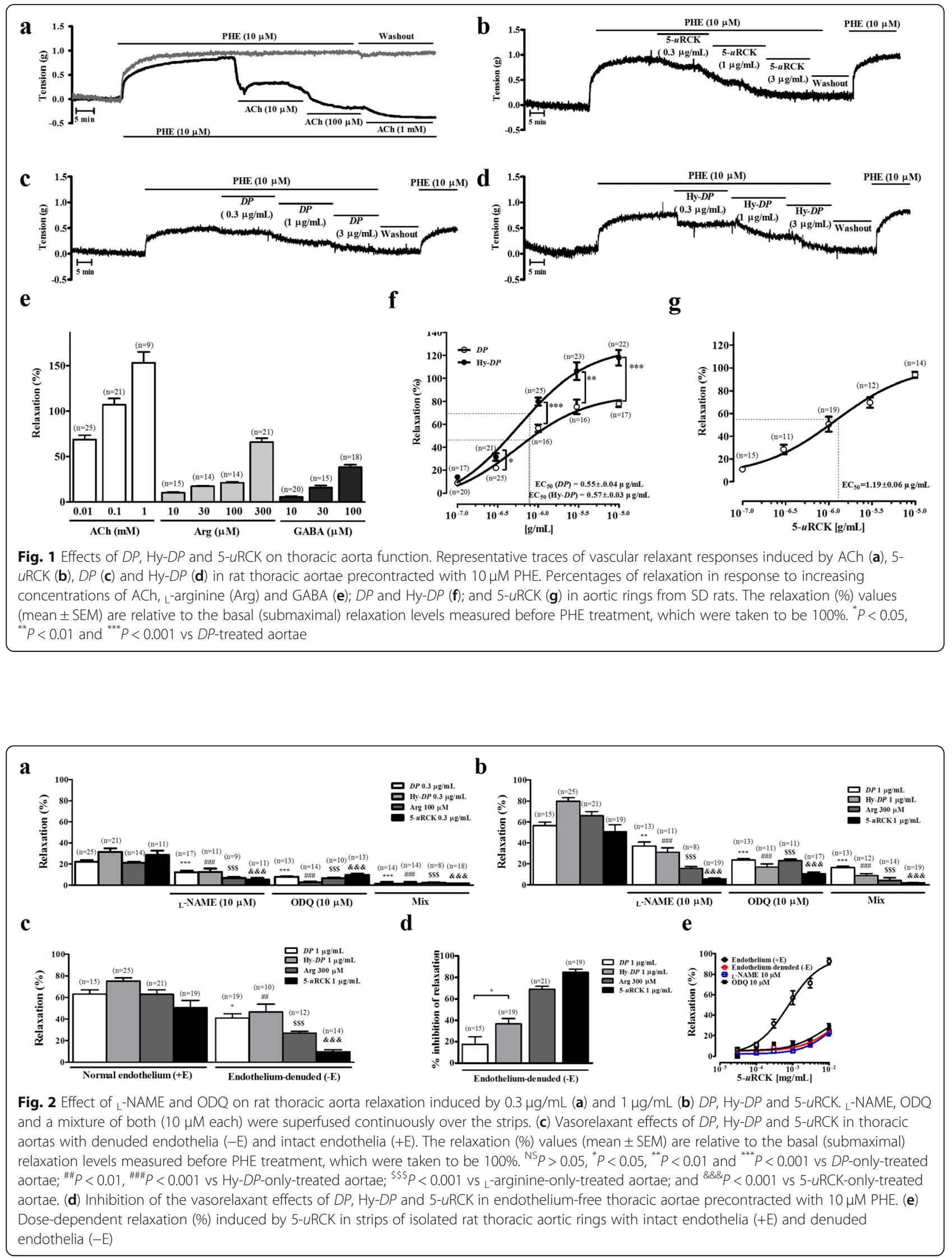

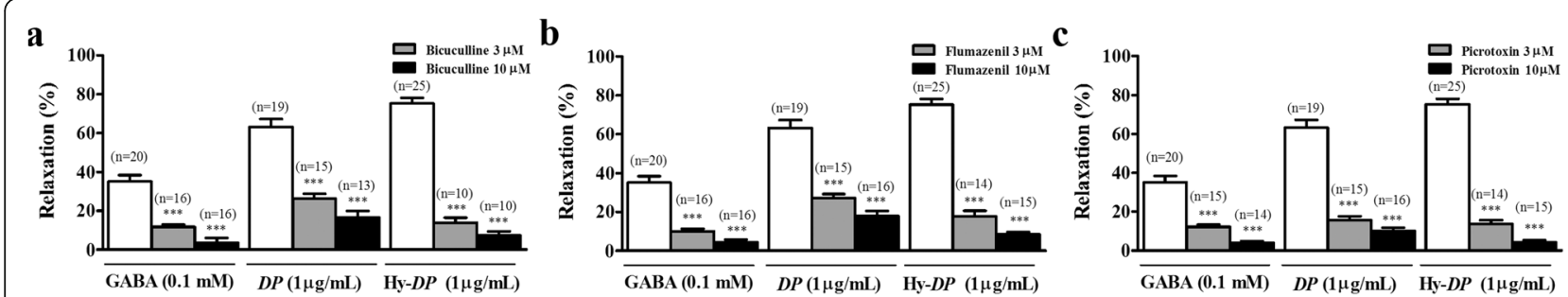

Fig. 3 Effects of bicuculline (a), flumazenil (b) and picrotoxin (c) on the relaxation responses induced by DP and Hy-DP in rat thoracic aortae precontracted with $10 \mu \mathrm{M}$ PHE. ${ }^{* * *} P<0.001$ vs no blockers

$\mathbf{a}$

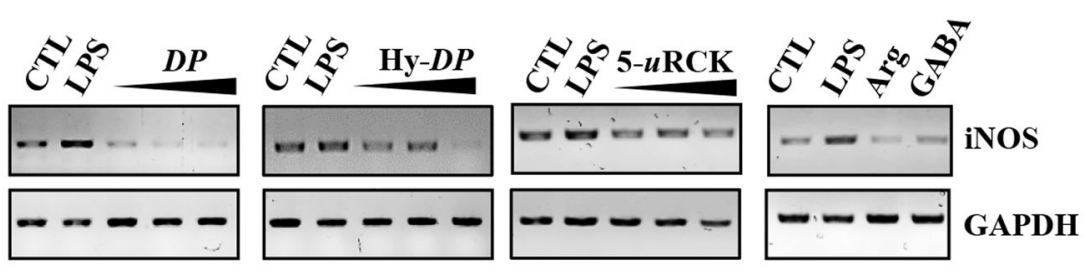

b

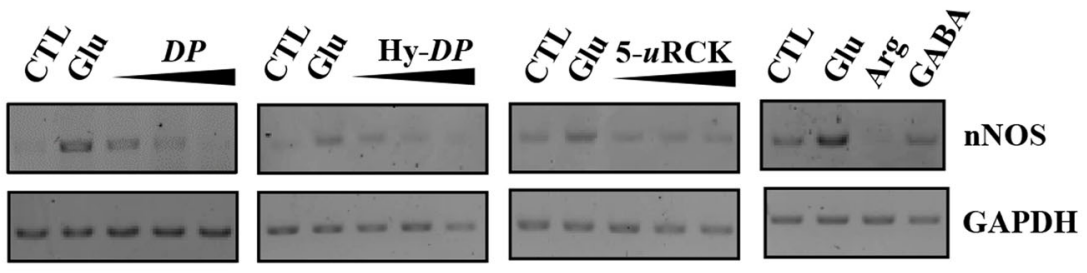

c

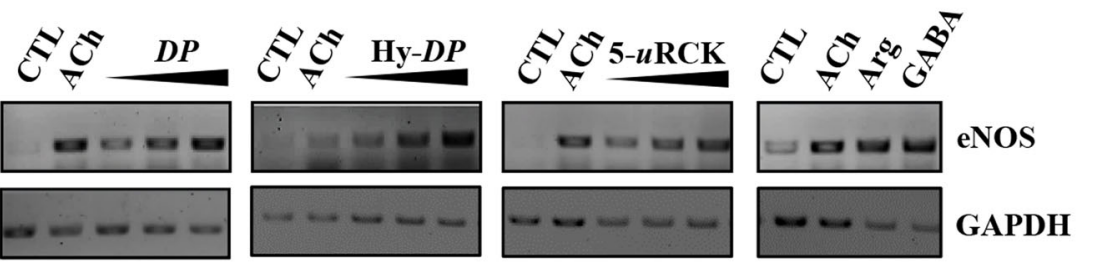

d

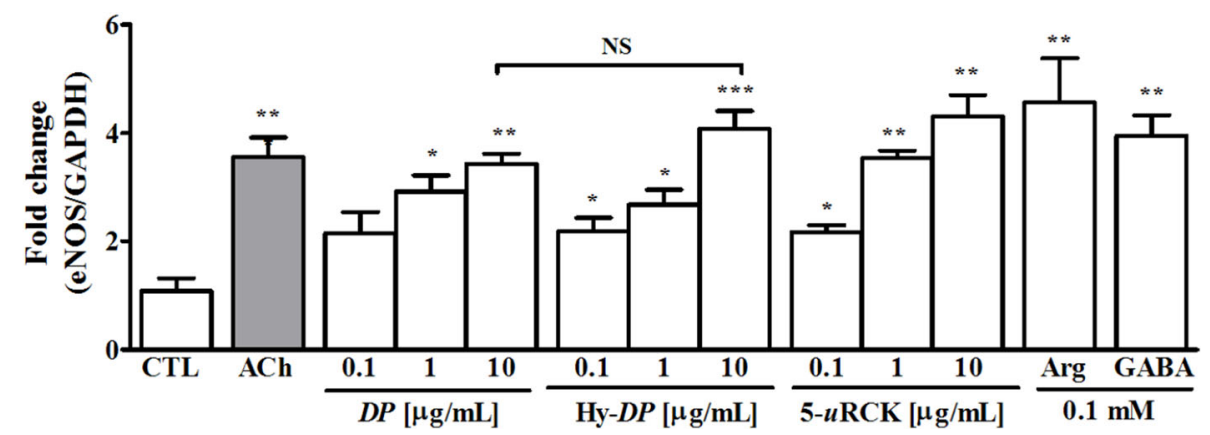

Fig. 4 Effects of DP, Hy-DP and 5-URCK on the expression of NOS isoforms at the mRNA level (as assessed by RT-PCR). a RT-PCR analysis of iNOS mRNA expression in murine RAW 264.7 macrophages. Activated cultures were stimulated for $6 \mathrm{~h}$ with $1 \mu \mathrm{g} / \mathrm{mL}$ LPS or individual extracts before extraction of RNA. $\mathbf{b}$ RT-PCR analysis of nNOS mRNA expression in cultured rat hippocampal neurons. Activated cultures were stimulated for $6 \mathrm{~h}$ with $50 \mu \mathrm{M}$ L-glutamate (Glu) or individual extracts before extraction of RNA. c RT-PCR analysis of eNOS mRNA expression in HUVECs. Activated cultures were stimulated for $6 \mathrm{~h}$ with $10 \mu \mathrm{M}$ ACh or individual extracts before extraction of RNA. d eNOS mRNA expression was detected by realtime quantitative RT-PCR. ${ }^{*} P<0.05,{ }^{* *} P<0.01$ and ${ }^{* * *} P<0.001$ vs the CTL group; NS, not significant 
We further investigated the effects of $D P, \mathrm{Hy}-D P$ and 5$u$ RCK on eNOS mRNA expression using RT-PCR. eNOS mRNA expression levels were significantly increased in DP-, Hy-DP- and 5-uRCK-stimulated HUVECs (Fig. 4c). Furthermore, eNOS was also strongly expressed in $\mathrm{L}^{\text {-arginine- }}$ and GABA-stimulated HUVECs. eNOS mRNA expression was confirmed by real-time qPCR (Fig. 4d). The eNOS mRNA levels in HUVECs were significantly higher in ACh-treated cells than in control cells and were significantly increased by the $D P, \mathrm{Hy}-D P$ and $5-u \mathrm{RCK}$ treatments, except for $0.1 \mu \mathrm{g} / \mathrm{mL} D P$ treatment.

\section{Hy-DP and 5-uRCK stimulate the production of NO}

To further clarify the eNOS-specific expression effects of $D P, \mathrm{Hy}-D P$ and 5-uRCK, we compared the amounts of NO produced by RAW 264.7 macrophages, cultured hippocampal neurons and HUVECs in vitro after the different treatments (Fig. 5). NO production was unaffected by both Hy-DP and 5-uRCK in RAW 264.7 macrophages and cultured hippocampal neurons, whereas exposure to slightly higher concentrations of $\mathrm{Hy}-D P$ or 5-uRCK significantly decreased NO production. Treatment with $30 \mu \mathrm{M}_{\mathrm{L}}$-arginine significantly decreased NO production in RAW 264.7 cells compared with control levels. Furthermore, compared with the control condition, $\mathrm{Hy}-D P$, $5-u R C K$ and ${ }_{L}$-arginine treatment significantly decreased NO production in cultured hippocampal neurons. As shown in Fig. 5c, however, HUVEC-mediated release of NO dose-dependently increased after treatment with $D P, \mathrm{Hy}-D P$ and 5-uRCK. Culture medium containing

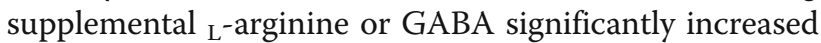
NO levels in endothelial cells. However, NO production was not further enhanced in the presence of $\mathrm{Hy}-\mathrm{DP}$ compared with $D P$ (Fig. 5c).

\section{Combined effects of Hy-DP and 5-uRCK on ACE activity inhibition}

As shown in Fig. 6a and b, the effects of different concentrations of $D P, \mathrm{Hy}-D P$ and 5- $u \mathrm{RCK}$ on ACE activity were examined in vitro. $D P$ and $5-u$ RCK both exhibited dose-dependent in vitro ACE inhibition activity, with $\mathrm{IC}_{50}$ values of $81.48 \pm 0.24 \mu \mathrm{g} / \mathrm{mL}$ and $19.74 \pm 0.09 \mu \mathrm{g} /$ $\mathrm{mL}$, respectively. Hy- $D P$ showed greater inhibitory activity ( $\mathrm{IC}_{50}$ value: $66.70 \pm 0.13 \mu \mathrm{g} / \mathrm{mL}$ ) than $D P$ but far less inhibitory activity than the 2:1 mixture ( $\mathrm{IC}_{50}$ value: $7.65 \pm 0.15 \mu \mathrm{g} / \mathrm{mL}$ ). However, ACE activity inhibition was unaffected by all concentrations of both ${ }_{\mathrm{L}}$-arginine and GABA (Fig. 6c).

\section{Combined effects of Hy-DP and 5-uRCK on CGMP- dependent PDE inhibition}

The cGMP-dependent PDE-inhibitory effects of DP, Hy$D P$ and $5-u$ RCK were tested and compared with those of 3-isobutyl-1-methylxanthine (IBMX), a PDE inhibitor drug (positive control). The $\mathrm{IC}_{50}$ value of IBMX was $24.2 \pm 1.14 \mu \mathrm{M}$ (data not shown). The highest cGMPdependent PDE inhibition percentage was observed for the $2: 1$ mixture $(10 \mu \mathrm{g} / \mathrm{mL}$ ) at $95.50 \pm 0.92 \%$ (Fig. $6 \mathrm{~d}$ and e). This mixture yielded an $\mathrm{IC}_{50}$ value of cGMPdependent PDE inhibition of $0.34 \pm 0.04 \mu \mathrm{g} / \mathrm{mL}$. However, as Fig. $6 \mathrm{f}$ shows, no significant changes in PDE inhibition were observed after treatment with varying doses of ${ }_{\mathrm{L}}$-arginine and GABA.

\section{Combined effects of Hy-DP and 5-uRCK on cAMP- dependent PDE inhibition}

The activity of PDEs, which are known to hydrolyze cAMP into inactive $5^{\prime}$ nucleotide monophosphates $\left(5^{\prime}\right.$-adenosine monophosphate [AMP]) [30], was not significantly altered by treatment with varying doses of ${ }_{\mathrm{L}}$-arginine and GABA (Fig. 6i). However, the highest cAMP-dependent PDE inhibition percentage was observed for the 2:1 mixture $(10 \mu \mathrm{g} / \mathrm{mL})$ at $89.64 \pm 2.70 \%$ (Fig. $6 \mathrm{~g}$ and $\mathrm{h}$ ). This mixture yielded an $\mathrm{IC}_{50}$ value of cAMP-dependent PDE inhibition of $1.68 \pm 0.25 \mu \mathrm{g} / \mathrm{mL}$.

\section{Combined effects of Hy-DP and 5-uRCK on isolated rat aortic rings precontracted with $\mathrm{PHE}$}

As shown in Fig. $7 \mathrm{a}$ and $\mathrm{b}$, the $1: 1$ mixture $\left(\mathrm{EC}_{50}\right.$ value: $2.68 \pm 0.11 \mu \mathrm{g} / \mathrm{mL}) \quad$ dose-dependently relaxed endothelium-intact aortic rings precontracted with PHE. The 2:1 mixture $\left(\mathrm{EC}_{50}\right.$ value: $\left.0.39 \pm 0.02 \mu \mathrm{g} / \mathrm{mL}\right)$ also dose-dependently relaxed endothelium-intact aortic rings precontracted with PHE. The maximal relaxant effects of the 1:1 mixture and 2:1 mixture on PHEinduced contraction were $65.58 \pm 3.97 \%$ and $130.71 \pm$ $4.77 \%$ at a concentration of $10 \mu \mathrm{g} / \mathrm{mL}$, respectively. Therefore, the 2:1 mixture exhibited the most potent vascular relaxant effect.

\section{Discussion}

This present study demonstrated, for the first time, that $\mathrm{Hy}-D P$ and 5- $u$ RCK induced significant endotheliumdependent and endothelium-independent relaxation in PHE-precontracted aortic rings. To investigate the involvement of $\mathrm{NO}$, the aortic rings were pretreated with ${ }_{L}$-NAME. Pretreatment with ${ }_{L}$-NAME completely abolished the vasorelaxation induced by $5-u$ RCK; however, it did not completely abolish the vasorelaxation induced by $\mathrm{Hy}-D P$. Interestingly, the relaxation induced by $5-u \mathrm{RCK}$, but not that induced by Hy-DP, was completely abolished in denuded aortic rings. These results indicated that 5-uRCK exhibited an endothelium-dependent vasodilator effect, while $\mathrm{Hy}-D P$ exhibited a partially endothelium-dependent vasodilator effect. Additionally, Hy- $D P$ and 5- $u$ RCK significantly increased nitrate/nitrite levels and eNOS expression in vitro, thereby increasing 
a

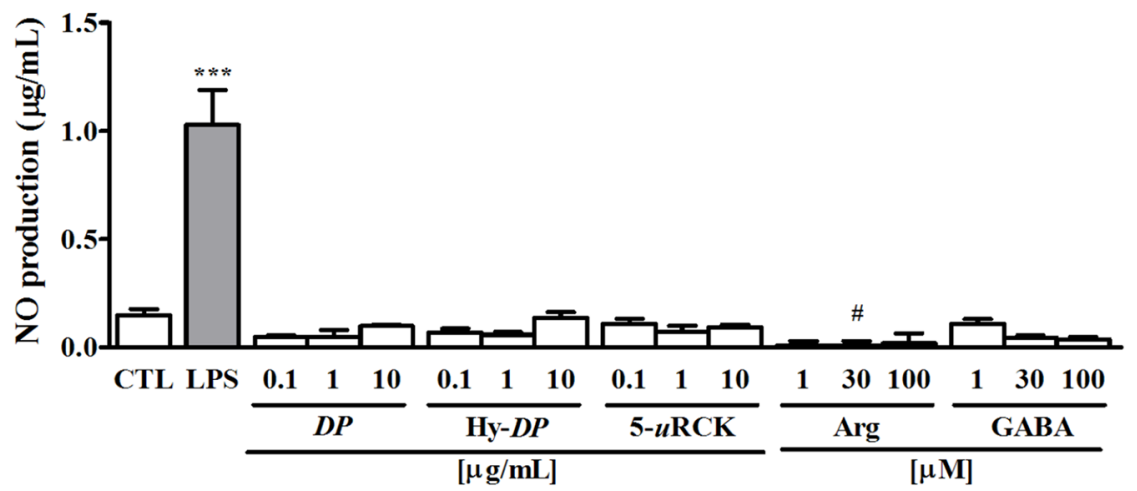

b

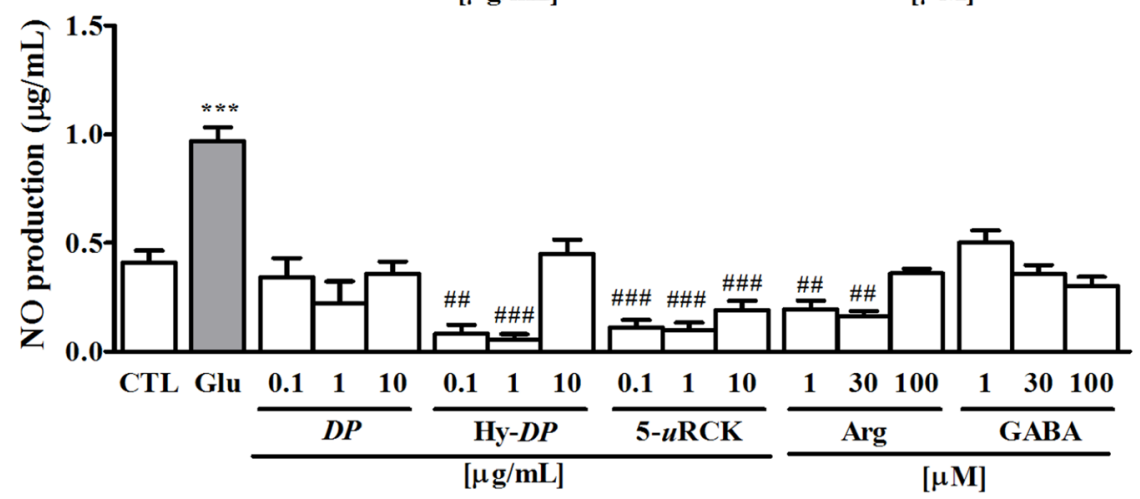

c

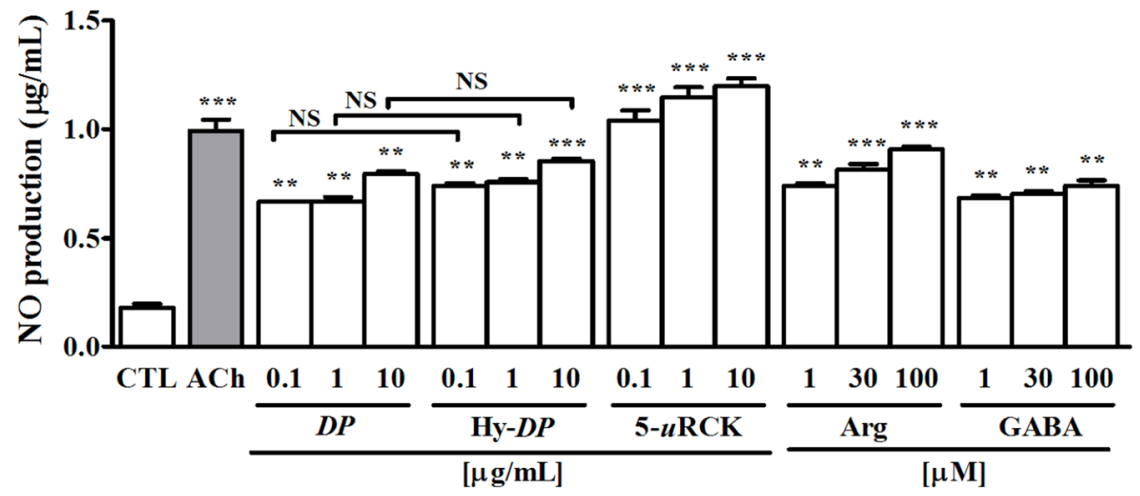

Fig. 5 Effects of DP, Hy-DP and 5-uRCK on NO levels. NO levels in murine RAW 264.7 macrophages, hippocampal neurons, and HUVECs treated with $D P, \mathrm{Hy}$-DP or 5-URCK. NO production at baseline (control; $C T L$ ) and after treatment with $1 \mu \mathrm{g} / \mathrm{mL}$ LPS or individual extracts in murine RAW 264.7 macrophages (a), at baseline and after treatment with $50 \mu \mathrm{M} \mathrm{Glu}$ or individual extracts in cultured rat hippocampal neurons (b), and at

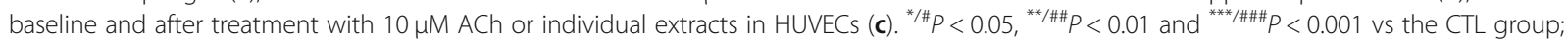
Symbols refers to the significant difference (* symbol: increase/\# symbol: decrease) of treated group to control. NS, not significant

NO bioavailability. Although ${ }_{\mathrm{L}}$-NAME is a nonspecific inhibitor of all three NOS isozymes, eNOS plays a major role in the development and maintenance of hypertension. This study addressed the specific effects of $\mathrm{Hy}-D P$ and $5-u \mathrm{RCK}$ on the neuronal and inducible NOS isozymes. The results confirmed that $\mathrm{Hy}-\mathrm{DP}$ and 5-uRCK did not affect the expression of neuronal or inducible NOS but specifically increased the expression of eNOS. Interestingly, combined treatment with $\mathrm{Hy}-\mathrm{DP}$ and 5$u$ RCK induced increased relaxation in PHE- precontracted aortic rings, producing additive effects compared with treatment with either Hy-DP of 5-uRCK alone. In particular, the most significant effect was observed when $\mathrm{Hy}-D P$ and 5 - $u$ RCK were mixed at a 2:1 ratio.

It is known that endothelial cells generate $\mathrm{NO}$ from $\mathrm{L}^{-}$ arginine via the catalytic action of eNOS [31]. Intracellu$\operatorname{lar}_{\mathrm{L}}$-arginine concentrations usually remain in the range of $0.8-2.0 \mathrm{mM}$, implying that the endothelium is always saturated with ${ }_{L}$-arginine as a substrate for constitutively 


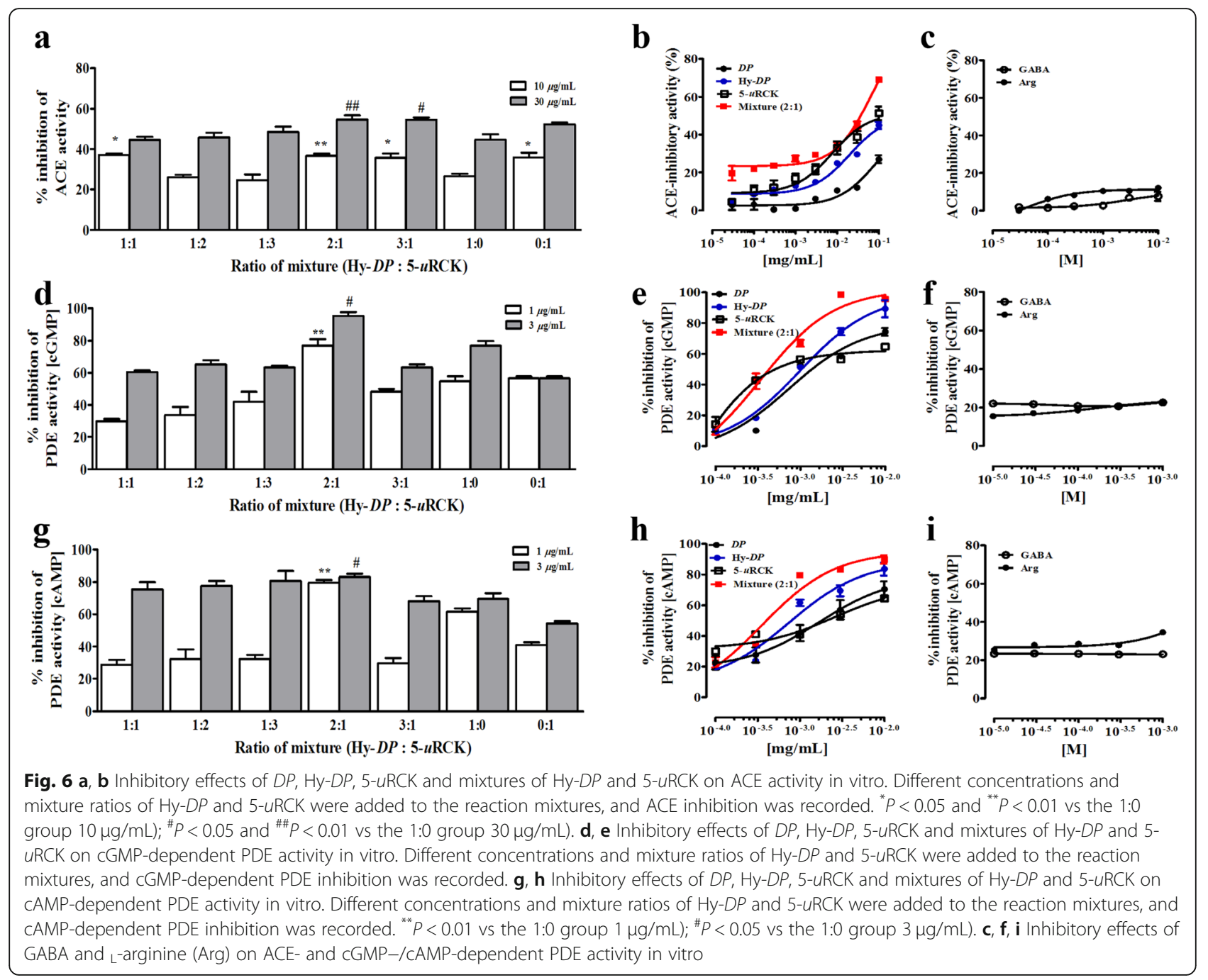

active eNOS-mediated NO synthesis. However, as the external supply of ${ }_{L}$-arginine decreases, ${ }_{L}$-arginine transcellular transport becomes the rate-limiting step in NO production. Therefore, NO released by endothelial cells is regarded as an important regulator of vascular function. We have previously established an enzymatic hydrolysis extraction method to amplify the ${ }_{\mathrm{L}}$-arginine content in $D P$ and Hy-DP [17]. The results showed that $\mathrm{L}$-arginine contained in Hy-DP could ameliorate vascular dysfunction caused by deficiency of $\mathrm{L}_{\mathrm{L}}$-arginine. However, the exact molecular mechanisms of $\mathrm{Hy}-D P$ - and 5$u$ RCK-activated $\mathrm{L}_{\mathrm{L}}$-arginine transport remain to be further studied.

The integrity of the vascular endothelium is pivotal for health, and the cardiovascular protective activity of the endothelium depends on its capacity to generate NO [32]. It is also known that inhibition of eNOS activity impacts the constitutive release of $\mathrm{NO}$ in vessel walls. The results of the present study with regard to both intact endothelia and eNOS activity showed that both Hy-
$D P$ and 5-uRCK mediated vasodilation at clinically useful doses. Therefore, we are conducting additional studies to identify effective concentration ranges and elucidate the detailed mechanisms using hypertension animal models, such as the spontaneously hypertensive rat (SHR) model and the 1 kidney-1 clip (1 K-1C) Goldblatt rat model of hypertension.

eNOS is one of the isoforms of the NOS family responsible for NO production in endothelial cells [33]. The activity of eNOS is highly regulated by its interaction with various proteins, such as calmodulin $(\mathrm{CaM})$, heat shock proteins, the B2 receptor, caveolin and dynamin-2 [34]. Phosphorylation by various protein kinases at serine residues and, to a lesser extent, threonine and tyrosine residues has been recently identified to be an important regulator of eNOS activity [34]. Phosphorylation at Ser1177 is carried out by protein kinase A (PKA) or GMP- and AMP-dependent kinases [34]. Although this study did not elucidate the detailed mechanisms involved in the phosphorylation of these proteins, 


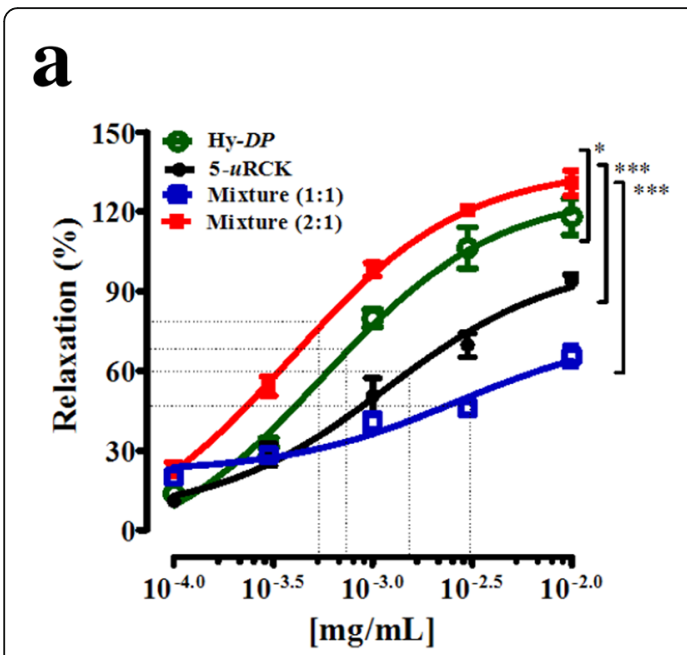

\section{b}

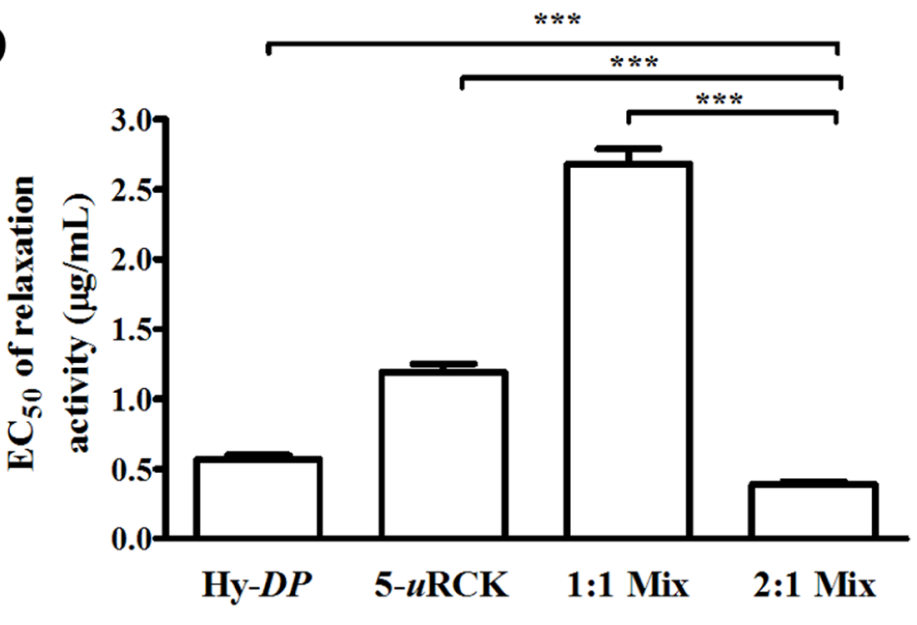

Fig. 7 Relaxation in response to increasing concentrations of $D P, H y-D P, 5-u R C K$ and $H y-D P / 5-u R C K$ mixtures in rat aortic rings. The concentration-response curves show the relaxation effects of DP, Hy-DP, 5-uRCK and mixtures of Hy-DP and 5- $u$ RCK on rat thoracic aortae precontracted with PHE in the presence of functional endothelium (a). Summary of the $\mathrm{EC}_{50}$ values of different extracts with regard to the relaxation of endothelium-intact aortic rings precontracted with PHE (b). All values are expressed as the means \pm SEMs

Hy- $D P$ and $5-u$ RCK were found to selectively increase eNOS expression. Therefore, we will follow up with this study to determine the effects of $\mathrm{Hy}-D P$ and $5-u \mathrm{RCK}$ on the phosphorylation of eNOS and its related proteins.

The ability of $\mathrm{Hy}-D P$ to induce relaxation in the presence of ${ }_{L}$-NAME or in the denuded aortic rings indicates the involvement of constituents that act through different vascular mechanisms, independent of the endothelium. We tested the hypotheses that GABA contained in $\mathrm{Hy}-D P$ exhibits a vasorelaxant effect and that $\mathrm{Hy}-D P$ regulates ACE- or PDE enzyme activity.

Previous studies have reported that a single oral administration of GABA $(0.5 \mathrm{mg} / \mathrm{kg})$ significantly lowers systolic blood pressure in SHRs [23] but not in normotensive rats and that the antihypertensive activity of GABA is dose-dependent at doses ranging from 0.05 to $5 \mathrm{mg} / \mathrm{kg}$ in SHRs [24]. Since $100 \mathrm{mg}$ of Hy-DP contains $2.8 \mathrm{mg}$ of GABA, as estimated from the HPLC data, we found that $\mathrm{Hy}-D P$ contains a high enough concentration of GABA to decrease blood pressure in SHRs.

Food products that inhibit ACE activity in vitro have been considered ideal candidates for alleviation of hypertension [35]. Moreover, one mechanism that has been proposed to explain the antihypertensive effect of the extract is the inhibitory effect of the extract on ACE. This present study demonstrated that $\mathrm{Hy}-\mathrm{DP}$ exhibited considerably stronger ACE-inhibitory activity $\left(\mathrm{IC}_{50}=\right.$ $66.70 \mu \mathrm{g} / \mathrm{mL})$ than $D P\left(\mathrm{IC}_{50}=81.48 \mu \mathrm{g} / \mathrm{mL}\right)$. However, $\mathrm{L}^{-}$ arginine and GABA did not show ACE-inhibitory activity. Furthermore, the cGMP-dependent PDE-inhibitory activity observed for $\mathrm{Hy}-\mathrm{DP} \quad\left(\mathrm{IC}_{50}=0.40 \mu \mathrm{g} / \mathrm{mL}\right)$ was considerably stronger than that of $D P\left(\mathrm{IC}_{50}=0.73 \mu \mathrm{g} /\right.$ $\mathrm{mL}$ ). However, $\mathrm{L}$-arginine and GABA did not show
ACE- or PDE-inhibitory activity. Therefore, the ACEand PDE-inhibitory activity of $D P$ and $\mathrm{Hy}-D P$ may be due to various flavonoids, such as quercetin. According to previous reports, flavonoids such as quercetin-2-O- $\alpha$ 6-caffeoyl-glycosyl- $\beta$-1,2-rhamnoside $\quad\left(\mathrm{IC}_{50}=158.9 \mu \mathrm{M}\right)$, quercetin-3-O- $\alpha-6$-p-coumaroyl-glycosyl- $\beta-1,2$-rhamnoside $\left(\mathrm{IC}_{50}=351.6 \mu \mathrm{M}\right)$, quercetin-3-O- $\beta$-glucopyranoside $\left(\mathrm{IC}_{50}=708.8 \mu \mathrm{M}\right)$ and quercetin-3-O- $\alpha$-arabinopyranoside $\left(\mathrm{IC}_{50}=320 \mu \mathrm{M}\right)$, have strong ACE-inhibitory activity $[36,37]$. Furthermore, many flavonoid-rich plants have been reported to exert ACE-inhibitory effects both in vitro and in vivo $[38,39]$. Researchers have even suggested that there might be an association between the consumption of flavonoid-rich foods and reductions in blood pressure. As in the case of ACE, the importance of flavonoid compounds for preservation of cardiovascular function and the links between flavonoid components and the NO/cGMP pathway have been emphasized [36]. However, changes in flavonoid content during the enzymatic hydrolysis extraction of $D P$ were not identified. Therefore, we need to clarify these findings in further research. We also intend to further study ACE-inhibitory activity and the levels of plasma endothelin-1 in hypertensive animal models such as the SHR model. A further possible mechanism of the antihypertensive effects of $\mathrm{Hy}-\mathrm{DP}$ and $5-u \mathrm{RCK}$ may be related to the pronounced PDE-inhibitory activity of these extracts. Reductions in NO synthesis or increases in NO degradation lead to decreases in cGMP formation, which promote vasoconstriction responses, platelet adhesion and proliferation of vascular smooth muscle cells, thus favoring vascular hypertrophy and occlusive vascular disease [40]. PDEs compose a class of enzymes that are capable of cleaving 
phosphodiester bonds in both cAMP and cGMP, which are important intracellular messengers that stimulate vascular smooth muscle relaxation. Orallo et al. [41] reported that the clear vasorelaxant effects of naringenin, a natural flavonoid, on rat aortic smooth muscle are probably mediated by increases in cytosolic cAMP and cGMP concentrations. As observed for the ACE-inhibitory effects, the increased PDE-inhibitory effects of Hy-DP are expected to be due to changes in flavonoid content that occur during the enzymatic hydrolysis step of Hy-DP production.

The cytotoxicity of extracts may be one factor involved in vascular endothelial-independent responses. We have tested and reported the cytotoxicity of $D P$ and $5-u R C K$ extracts in various cells through similar studies. As a result, we have not observed any cytotoxicity of these extracts up to $300 \mu \mathrm{g} / \mathrm{mL}$ in $3 \mathrm{~T} 3-\mathrm{L} 1$ cells $[5,6,21]$, HepG2 cells [3, 4, 42], human gastric epithelial cell [43], mouse melanoma cells [44] and rat primary hepatocytes [45]. Although this study did not provide direct cytotoxicity results, it is expected that there will be no cytotoxicity according to the results of our previous reports. Therefore, in the next study, it is necessary to study the direct effect on the cytotoxicity of the extract by separating vascular endothelial and muscle cells.

\section{Conclusions}

The main finding of the present study was that the extracts Hy-DP and 5-uRCK exert vasorelaxant effects through slightly different endothelium-dependent or endothelium-independent mechanisms. The vasorelaxant effects of Hy-DP and 5- $u$ RCK may be associated with increases in eNOS gene expression and inhibition of ACE and PDE activity. The vasorelaxant effect of Hy$D P$ might be due mostly to the effects of ${ }_{\mathrm{L}}$-arginine and GABA and partially to the effects of polyphenols, which have vasodilatory activity. Interestingly, combined treatment with $\mathrm{Hy}-D P$ and 5- $u$ RCK was more effective than treatment with $\mathrm{Hy}-D P$ or $5-u \mathrm{RCK}$ alone. Collectively, these findings suggest that a mixture of $\mathrm{Hy}-\mathrm{DP}$ and 5$u$ RCK could be used for prevention of or as an adjuvant therapy for hypertension. However, more studies are required to evaluate the detailed mechanisms in experimental animal models of hypertension and to determine the safety and efficacy of such a mixture in clinical conditions in humans.

\section{Abbreviations}

ACE: Angiotensin-converting enzyme; ACh: Acetylcholine chloride; CAMP: Cyclic 3',5'-adenosine monophosphate; cGMP: Cyclic 3',5'-guanosine monophosphate; CVD: Cardiovascular disease; DP: Dendropanax morbiferus $\mathrm{H}$. Léveille extract; eNOS: Endothelial nitric oxide synthase; $\mathrm{EC}_{50}$ : Half maximal effective concentration; GABA: $\gamma$-aminobutyric acid; GAPDH: Glyceraldehyde 3-phosphate dehydrogenase; GC: Guanylate cyclase; HUVEC: Human umbilical vein endothelial cell; Hy-DP: Enzymatically hydrolyzed Dendropanax morbiferus $\mathrm{H}$. Léveille extract; $I_{5}$ : Half maximal inhibitory concentration;
iNOS: Inducible nitric oxide synthase; L-NAME: $\mathrm{N}^{\omega}{ }^{\omega}$-nitro-_-arginine methyl ester; NO: Nitric oxide; NOS: Nitric oxide synthase; nNOS: Neuronal nitric oxide synthase; ODQ: $1 \mathrm{H}-[1,2,4]$ oxadiazolo [4,3-a]quinoxalin-1-one; PDE: Phosphodiesterase; PHE: Phenylephrine hydrochloride; 5-uRCK: 5\% unripe Rubus coreanus Miquel ethanol extract

\section{Acknowledgments}

We sincerely appreciate other colleagues in our laboratory for their help and effort in this study.

\section{Authors' contributions}

$\mathrm{SP}, \mathrm{KHL}$, JSK and SK participated in research design. KHL contributed new regents or analytical tools. SP and KHL performed data analysis. WSK and SK wrote or contributed to the writing of the manuscript. All authors read and approved the final manuscript.

\section{Funding}

This research was supported by a grant from the Korea Institute of Planning \& Evaluation for Technology in Food, Agriculture Forestry \& Fisheries (IPET) through the High Value-added Food Technology Development Program (grant number: 316065-3 and 116032-3). The funding body did not play a role in the study design, performance, data collection and analysis, decision to publish, or preparation/writing of the manuscript. The publication fee is supported by the former (316065-3).

\section{Availability of data and materials}

All data and analyses in the current study are available from the corresponding author upon reasonable request.

\section{Ethics approval and consent to participate}

The experiment was conducted according to the Directive 2010/63/EU of the European Parliament and of the counsel on the protection of animals used for scientific purposes [26].

The study was approved by the institutional animal care and use committee (IACUC) of the Bioresources and Technology (B\&Tech) Co., Ltd., Republic of Korea (Approval number: BT-008-2017). All efforts were made to minimize animal suffering and to reduce the number of animals used.

\section{Consent for publication}

All the participating authors read the manuscript and give consent for publication.

\section{Competing interests}

The authors declare that they have no competing interests.

Received: 9 March 2020 Accepted: 1 June 2020

Published online: 22 June 2020

\section{References}

1. Turnbull F. Blood pressure lowering treatment Trialists' collaboration, effects of different blood-pressure-lowering regimens on major cardiovascular events: results of prospectively-designed overviews of randomized trials. Lancet. 2003;362:1527-35. https://doi.org/10.1016/s0140-6736(03)14739-3.

2. Conlin PR, Chow D, Miller ER, et al. The effect of dietary patterns on blood pressure control in hypertensive patients: results from the dietary approaches to stop hypertension (DASH) trial. Am J Hypertens. 2000;13:94955. https://doi.org/10.1016/s0895-7061(99)00284-8.

3. Jung M-A, Cho S-H, Lee SY, et al. Effects of unripe Rubus coreanus Miquel extract on improvement of lipid metabolism in C57BL/6 mice fed a highcholesterol diet. J Korean Soc Food Sci Nutr. 2014;43:650-5. https://doi.org/ 10.3746/jkfn.2014.43.5.650.

4. Lee $\mathrm{KH}$, Jeong $\mathrm{E}$, Jang $\mathrm{G}$, et al. Unripe Rubus coreanus Miquel extract containing ellagic acid regulates AMPK, SREBP-2, HMGCR and INSIG-1 signaling and cholesterol metabolism in vitro and in vivo. Nutrients. 2020; 12(3):610. https://doi.org/10.3390/nu12030610.

5. Jung M-A, Cho S-H, Lee SY, et al. Anti-obesity effects on unripe Rubus coreanus Miquel extract in high fat diet-induced obese mice. IJBCRR. 2014;5: 20-6. https://doi.org/10.9734/IJBCRR/2015/12680.

6. Oh DR, Kim Y, Choi EJ, et al. Antiobesity effects of unripe Rubus coreanus Miquel and its constituents: an in vitro and in vivo characterization of the 
underlying mechanism. Evid Based Complement Alternat Med. 2016;2016: 4357656. https://doi.org/10.1155/2016/4357656.

7. Panchal SK, Ward L, Brown L. Ellagic acid attenuates high-carbohydrate, high-fat diet-induced metabolic syndrome in rats. Eur J Nutr. 2013;52:55968. https://doi.org/10.1007/s00394-012-0358-9.

8. Bobinaite $R$, Viškelis $P$, Venskutonis PR. Variation of total phenolics, anthocyanins, ellagic acid and radical scavenging capacity in various raspberry (Rubus spp.) cultivars. Food Chem. 2012;132:1495-501. https://doi. org/10.1016/j.foodchem.2011.11.137.

9. Yang HM, Oh SM, Lim SS, Shin HK, Oh YS, Kim JK. Antiinflammatory activities of Rubus coreanus depend on the degree of fruit ripening. Phytother Res. 2008;22:102-7. https://doi.org/10.1002/ptr.2274.

10. Ahmad M, Masood S, Sultana S, Hadda TB, Bader A, Zafar M. Report: antioxidant and nutraceutical value of wild medicinal Rubus berries. Pak $J$ Pharm Sci. 2015;28:241-7 https://www.ncbi.nlm.nih.gov/pubmed/25553701.

11. Bae K. The medicinal plants of Korea. Seoul: Kyo-Hak Publishing; 2000 .

12. Hyun TK, Kim MO, Lee $H$, et al. Evaluation of anti-oxidant and anti-cancer properties of Dendropanax morbifera Léveille. Food Chem. 2013;141:194755. https://doi.org/10.1016/j.foodchem.2013.05.021.

13. Moon HI. Antidiabetic effects of dendropanoxide from leaves of Dendropanax morbifera Leveille in normal and streptozotocin-induced diabetic rats. Hum Exp Toxicol. 2011;30:870-5. https//doi.org/10.1177/0960327110382131.

14. Chung IM, Kim MY, Park WH, Moon HI. Antiatherogenic activity of Dendropanax morbifera essential oil in rats. Pharmazie. 2009;64:547-9. https://doi.org/10.1691/ph.2009.9555.

15. Hyun TK, Ko YJ, Kim EH, Chung IM, Kim JS. Anti-inflammatory activity and phenolic composition of Dendropanax morbifera leaf extracts. Ind Crop Prod. 2015;74:263-70. https://doi.org/10.1016/j.indcrop.2015.05.002.

16. Lee $\mathrm{KH}, \mathrm{Na} \mathrm{HJ}$, Song $\mathrm{CK}$, et al. Quercetin quantification in a Jeju Dendropanax morbifera Lev. Extract by varying different parts, harvest times, and extraction solvents. Korean J. Food Preserv. 2018;25:344-50. https://doi. org/10.11002/kjfp.2018.25.3.344

17. Lee KH, Kim S. Optimal enzymatic hydrolysis conditions for increased production of -arginine and GABA in Dendropanax morbifera Lev. Leaves Korean J Food Preserv. 2019;26:289-99. https://doi.org/10.11002/kjfp.2019.26. 3.289

18. Siasos G, Tousoulis D, Vlachopoulos C, et al. Short-term treatment with $L^{-}$ arginine prevents the smoking-induced impairment of endothelial function and vascular elastic properties in young individuals. Int J Cardiol. 2008;126: 394-9. https://doi.org/10.1016/.i.jcard.2007.04.057.

19. Shimada M, Hasegawa T, Nishimura C, et al. Anti-hypertensive effect of $\gamma^{-}$ aminobutyric acid (GABA)-rich Chlorella on high-normal blood pressure and borderline hypertension in placebo-controlled double blind study. Clin Exp Hypertens. 2009;31:342-54. https://doi.org/10.1080/10641960902977908.

20. Williford DJ, Hamilton BL, Souza JD, et al. Central nervous system mechanisms involving GABA influence arterial pressure and heart rate in the cat. Circ Res. 1980;47:80-8. https://doi.org/10.1161/01.res.47.1.80.

21. Abe $Y, U$ memura $S$, Sugimoto $K$, et al. Effect of green tea rich in $Y^{-}$ aminobutyric acid on blood pressure of Dahl salt-sensitive rats. Am J Hypertens. 1995;8:74-9. https://doi.org/10.1016/0895-7061(94)00141-w.

22. Aoki H, Furuya $Y$, Endo $Y$, Fujimoto K. Effect of $Y$-aminobutyric acid-enriched tempeh-like fermented soybean (GABA-tempeh) on the blood pressure of spontaneously hypertensive rats. Biosci Biotechnol Biochem. 2003;67:1806-8. https://doi.org/10.1271/bbb.67.1806.

23. Hayakawa K, Kimura M, Kamata K. Mechanism underlying Y-aminobutyric acidinduced antihypertensive effect in spontaneously hypertensive rats. Eur J Pharmacol. 2002:438:107-13. https://doi.org/10.1016/s0014-2999(02)01294-3.

24. Hayakawa K, Kimura M, Kasaha K, et al. Effect of a $y$-aminobutyric acidenriched dairy product on the blood pressure of spontaneously hypertensive and normotensive Wistar-Kyoto rats. Br J Nutr. 2004;92:411-7. https://doi.org/10.1079/bjin20041221.

25. Myoung HY, Shakina YS, Sungeun A, et al. Anti-obesity effect of gold nanoparticles from Dendropanax morbifera Léveille by suppression of triglyceride synthesis and downregulation of PPARY and CEBPa signaling pathways in 3T3-L1 mature adipocytes and HepG2 cells. Curr Nanosci. 2020; 16:198-203. https://doi.org/10.2174/1573413716666200116124822.

26. The European Parliament and the Council of the European Union. Directive 2010/63/EU of the European parliament and of the council of 22 September 2010 on the protection of animals used for scientific purposes. Off J Eur Union. 2010;276:33-79. https:/eur-lex.europa.eu/LexUriServ/LexUriServ.do?uri=OJ:L:201 0:276:0033:0079:EN:PDF.
27. Kim S, Ahn K, Oh TH, et al. Inhibitory effect of ginsenosides on NMDA receptor-mediated signals in rat hippocampal neurons. Biochem Biophys Res Commun. 2002;296:247-54. https://doi.org/10.1016/s0006291x(02)00870-7.

28. Romero M, Toral M, Gómez-Guzmán $M$, et al. Antihypertensive effects of oleuropein-enriched olive leaf extract in spontaneously hypertensive rats. Food Funct. 2016;7:584-93. https://doi.org/10.1039/c5fo01101a.

29. Holmquist B, Bünning P, Riordan JF. A continuous spectrophotometric assay for angiotensin converting enzyme. Anal Biochem. 1979;95:540-8. https:// doi.org/10.1016/0003-2697(79)90769-3.

30. von Bülow V, Rink L, Haase H. Zinc-mediated inhibition of cyclic nucleotide phosphodiesterase activity and expression suppresses TNF-alpha and IL-1 beta production in monocytes by elevation of guanosine $3^{\prime}, 5^{\prime}$-cyclic monophosphate. J Immunol. 2005;175:4697-705. https://doi.org/10.4049/ jimmunol.175.7.4697.

31. Closs El, Simon A, Vékony N, Rotmann A. Plasma membrane transporters for arginine. J Nutr. 2004;134(10 Suppl):2752S-67S. https://doi.org/10.1093/jn/ 134.10.2752S.

32. Blume-Jensen $P$, Hunter T. Oncogenic kinase signaling. Nature. 2001;411: 355-65. https://doi.org/10.1038/35077225.

33. Jia S, Liu Z, Zhang S, et al. Essential roles of PI(3)K-p110 3 in cell growth, metabolism and tumorigenesis. Nature. 2008;454:776-9. https://doi.org/10. 1038/nature07091.

34. Fulton D, Gratton JP, Sessa WC. Post-translational control of endothelial nitric oxide synthase: why isn't calcium/calmodulin enough? I Pharmacol Exp Ther. 2001;299:818-24 http://jpet.aspetjournals.org/content/299/3/818.

35. Guerrero MF, Puebla P, Carrón R, et al. Quercetin 3,7-dimethyl ether: a vasorelaxant flavonoid isolated from Croton schiedeanus Schlecht. J Pharm Pharmacol. 2002;54:1373-8. https://doi.org/10.1211/002235702760345455.

36. Oh H, Kang DG, Kwon JW, et al. Isolation of angiotensin converting enzyme (ACE) inhibitory flavonoids from Sedum sarmentosum. Biol Pharm Bull. 2004;27:2035-7. https://doi.org/10.1248/bpb.27.2035.

37. Loizzo MR, Said A, Tundis R, et al. Inhibition of angiotensin converting enzyme (ACE) by flavonoids isolated from Ailanthus excelsa (Roxb) (Simaroubaceae). Phytother Res. 2007;21:32-6. https://doi.org/10.1002/ptr. 2008

38. Kameda $\mathrm{K}$, Takaku T, Okuda $\mathrm{H}$, et al. Inhibitory effects of various flavonoids isolated from leaves of persimmon on angiotensin-converting enzyme activity. J Nat Prod. 1987;50:680-3. https://doi.org/10.1021/np50052a017.

39. Actis-Goretta L, Ottaviani II, Fraga CG. Inhibition of angiotensin converting enzyme activity by flavanol-rich foods. J Agric Food Chem. 2006;54:229-34. https://doi.org/10.1021/jf052263o.

40. Forte $\mathrm{P}$, Copland M, Smith LM, et al. Basal nitric oxide synthesis in essential hypertension. Lancet. 1997;349:837-42. https://doi.org/10.1016/S01406736(96)07631-3.

41. Orallo F, Camiña M, Alvarez E, et al. Implication of cyclic nucleotide phosphodiesterase inhibition in the vasorelaxant activity of the citrus-fruits flavonoid (+/-)-naringenin. Planta Med. 2005;71:99-107. https://doi.org/10. 1055/s-2005-837774

42. Hwang K, Kim J, Kim S. Eliminatory effect of functional drink added with several medicinal herb complex extracts on ethanol-induced blood alcohol concentration and hangover in rat. J Chitin Chitosan. 2019;24:33-41. https:// doi.org/10.17642/jcc.24.1.5.

43. Kim G, Kim JE, Kang MJ, et al. Inhibitory effect of 1-tetradecanol on Helicobacter pylori-induced production of interleukin-8 and vascular endothelial growth factor in gastric epithelial cells. Mol Med Rep. 2017;16: 9573-8. https://doi.org/10.3892/mmr.2017.7793.

44. Lee S, Choi E-J, Bae D, Lee D-W, Kim S. Effects of 1-tetradecanol and $\beta$ sitosterol Isolated from Dendropanax morbifera Lev. on skin whitening, moisturizing and preventing hair loss. J Soc Cosmetic Scientists Korea. 2015; 41:73-83. https://doi.org/10.15230/SCSK.2015.41.1.73.

45. Bae D, Kim J, Lee S, et al. Hepatoprotective effects of aqueous extracts from leaves of Dendropanax morbifera leveille against alcohol-induced hepatotoxicity in rats and in vitro antioxidant effects. Food Sci Biotechnol. 2015;24:1495-503. https://doi.org/10.1007/s10068-015-0193-x.

\section{Publisher's Note}

Springer Nature remains neutral with regard to jurisdictional claims in published maps and institutional affiliations. 